\title{
Role of CFTR expressed by neutrophils in modulating acute lung inflammation and injury in mice
}

\author{
Xiao Su $\cdot$ Mark R. Looney $\cdot$ Hang (Emily) Su $\cdot$ \\ Jae Woo Lee $\cdot$ Yuanlin Song $\cdot$ Michael A. Matthay
}

Received: 25 October 2010/Revised: 22 December 2010/Accepted: 15 January 2011/Published online: 8 February 2011

(C) The Author(s) 2011. This article is published with open access at Springerlink.com

\begin{abstract}
Objective and design Cystic fibrosis transmembrane conductance regulator (CFTR) regulates infection and inflammation. In this study, we investigated whether a lack of functional CFTR in neutrophils would promote lipopolysaccharide (LPS)-induced lung inflammation and injury.

Materials and methods CFTR-inhibited or F508delCFTR-mutated neutrophils were stimulated with LPS and cultured to evaluate production of cytokines and NF- $\kappa \mathrm{B}$ activation. Wild-type mice were reconstituted with F508del neutrophils or bone marrow and then intratracheally challenged with LPS to observe lung inflammatory response.

Results Pharmacologic inhibition and genetic mutation of CFTR in neutrophils activated NF- $\kappa \mathrm{B}$ and facilitated macrophage inflammatory protein-2 (MIP-2) and tumor necrosis factor- $\alpha$ (TNF- $\alpha$ ) production. Wild-type mice reconstituted with F508del neutrophils and bone marrow
\end{abstract}

Responsible Editor: Liwu Li.

X. Su $(\bowtie) \cdot$ M. R. Looney · H. (Emily)Su .

J. W. Lee $\cdot$ M. A. Matthay

Cardiovascular Research Institute, University of California,

San Francisco, HSW 825, 505 Parnassus AVE,

San Francisco, CA 94143-0130, USA

e-mail: suxiao1@yahoo.com

M. R. Looney · M. A. Matthay

Department of Medicine, University of California,

San Francisco, San Francisco, CA, USA

J. W. Lee · Y. Song · M. A. Matthay

Department of Anesthesia and Perioperative Care,

University of California, San Francisco,

San Francisco, CA, USA had more severe lung inflammation and injury after LPS challenge compared to wild-type mice receiving wild-type neutrophils or bone marrow reconstitution.

Conclusions Lack of functional CFTR in neutrophils can promote LPS-induced acute lung inflammation and injury.

Keywords Cystic fibrosis transmembrane conductance regulator · Neutrophils · Cytokine - Lipopolysaccharide · Bone marrow transplantation

\section{Introduction}

There is evidence that an ion channel (sodium-potassiumchloride cotransporter, NKCC1) can regulate the inflammatory response to lung infection and sepsis $[1,2]$. There are also studies indicating that another chloride channel, cystic fibrosis transmembrane conductance regulator (CFTR), modulates proinflammatory responses [3, 4]. Mutation of CFTR can exaggerate lung inflammation through increasing cytokine production and activating NF$\kappa \mathrm{B}$ in lung epithelial cells [5, 6]. Inhibition of CFTR in tracheal epithelial cells by CFTRinh-172 can also mimic proinflammatory profiles [7]. CFTR may be a negative regulator of NF- $\kappa$ B through which innate immune response and inflammation is mediated [8].

It has been reported that CFTR can be expressed by alveolar macrophages and neutrophils. Alveolar macrophages and neutrophils lacking functional CFTR are unable to efficiently clear lung bacterial infection in cystic fibrosis $[9,10]$ and are more proinflammatory [11]. Bruscia et al. [12] have further confirmed that bone marrow-derived macrophages (BMDM) and alveolar macrophages from CFTR knockout mice can contribute to the elevated cytokine production in response to LPS stimulation. 
Comparison of cytokine production by blood neutrophils from $\mathrm{CF}$ patients and from control subjects showed significantly increased IL- 8 and decreased IL-1ra release by CF neutrophils [13].

It is well-known that deficiency of CFTR leads to cystic fibrosis, which is primarily a chronic disease of large airways that are frequently infected by Pseudomonas aeruginosa [14]. Here, we should clarify that the purpose of this study was focused on the modulatory role of CFTR expressed by neutrophils in the sepsis-induced acute lung inflammation and injury, since Gram-negative bacteriainduced severe sepsis is a leading cause of acute lung injury. Studies have showed that CFTR is expressed at significant levels in distal areas of the lung, both in small airways (bronchioles) and in alveolar epithelial cells [15, 16] where acute lung inflammation and injury can develop as a result of lung infections or sepsis [17]. CFTR is also expressed in alveolar macrophages [9], which are native immunoregulatory cells for alveolar infection. Neutrophils are key players for sepsis-induced acute lung inflammation and injury $[17,18]$. In response to the challenge of endotoxin or bacteria, alveolar macrophages, and especially neutrophils, can be activated leading to acute lung inflammation and injury $[17,18]$.

Therefore, the objectives of this study were to test (1) whether Escherichia coli endotoxin [lipopolysaccharide (LPS)] stimulation affects CFTR expression in neutrophils; (2) whether inhibition and mutation of CFTR in neutrophils alters the activity of NF- $\kappa \mathrm{B}$ and proinflammatory cytokine production after LPS stimulation; (3) whether pharmacologic inhibition or mutation of CFTR promotes LPSinduced acute lung injury, and (4) whether neutrophils with mutated CFTR are more proinflammatory than wild-type neutrophils. Our overall objective was to test whether CFTR expressed by neutrophils is a modulator of endotoxin-induced acute lung injury.

\section{Materials and methods}

\section{Reagents}

CFTR $_{\text {inh-172 }}$ (thiazolidinone CFTR inhibitor, 3-[(3-trifluoromethyl) phenyl]-5-[(4-carboxyphenyl) methylene]-2thioxo-4-thiazolidinone) was purchased from EMD Biosciences (http://www.emdbiosciences.com) [7, 19]. MalH-2 (di-sulfonate glycine hydrazide, endotoxin free), a water soluble CFTR inhibitor, was synthesized by A. Verkman's laboratory at the University California San Francisco (UCSF) [20]. BMS-345541, an IKK-2 inhibitor was purchased from Calbiochem (San Diego, CA). Rabbit antiCFTR polyclonal antibody (H-182) was from Santa Cruz Biotechnology (Santa Cruz, CA).
Animals

Eight- to ten-week old CD1 wild-type and F508del-CF mice were obtained from A. Verkman (UCSF) for these studies. CFTR mutation nomenclature was in accordance with CFTR Mutation HGVS Nomenclature stated on the GeT-RM website (http://wwwn.cdc.gov/dls/genetics/ rmmaterials/default.aspx). Generation and genotyping procedures of F508del-CF mice were described previously $[21,22]$. The F508del-CF mice were back-crossed into a $\mathrm{CD} 1$ genetic background (>eight generations) and bred at the UCSF animal facility. Anesthesia was induced with an intraperitoneal injection (IP) of a mixture of ketamine $(90 \mathrm{mg} / \mathrm{kg})$ and xylazine $(10 \mathrm{mg} / \mathrm{kg})$. The Committee on Animal Research of the University of California, San Francisco approved all the protocols.

LPS-induced acute lung injury mouse model

A previously developed direct visualization instillation (DVI) method [23] was used to instill LPS (Sigma, E. coli 0111:B4, $5 \mathrm{mg} / \mathrm{kg}$ ) into the airspaces of the lung. To test the modulatory effects of CFTR in sepsis-induced acute lung injury, LPS from E. coli instead of Pseudomonas aeruginosa or its endotoxin (as a common pathogen for cystic fibrosis lung inflection) was used thorough the experiments. The LPS dosage $(5 \mathrm{mg} / \mathrm{kg})$ was chosen aiming to induce a robust lung inflammation and injury at $24 \mathrm{~h}$ as previously reported $[17,24]$ and, at this dosage, no mice died of intratracheal exposure of E. coli endotoxin.

\section{Administration of CFTR inhibitor (MalH-2)}

In the in vitro studies, $100 \mu \mathrm{M}$ MalH-2 induced higher proinflammatory responses in neutrophils than $20 \mu \mathrm{M}$ MalH-2, as reported previously in the epithelial cells [20]. In the in vivo studies, MalH-2 was given IP (dissolved in PBS, $3 \mathrm{mg} / \mathrm{kg}$ ) $20 \mathrm{~min}$ before intratracheal challenge with LPS $(5 \mathrm{mg} / \mathrm{kg})$, and repeated again $(3 \mathrm{mg} / \mathrm{kg}) 12 \mathrm{~h}$ later. MalH-2 $(2 \mathrm{mg} / \mathrm{kg})$ was also administrated intratracheally 20 min before intratracheal challenge with LPS. The dosage of MalH-2 was selected as previously reported and there were no detectable toxicity in cell cultures (50-100 $\mu \mathrm{M}$ for 2 days) and in mice $(4-8 \mathrm{mg} / \mathrm{kg}$, twice daily for 4 days) [20].

Measurement of extravascular lung water

At designated time points after LPS challenge, the mice were euthanized by giving an IP injection of a mixture of ketamine and xylazine and following by a cervical dislocation. The gravimetric determination of extravascular lung water has been described previously [18]. 
Measurements of lung myeloperoxidase activity

The activity of myeloperoxidase (MPO) was measured using a kinetic assay using standard methods [24, 25].

Bronchoalveolar lavage, protein levels, neutrophil count

We used standard methods as previously described [23, 24].

Neutrophil isolation and culture

The procedure of neutrophil isolation has been described previously [26]. The isolated neutrophils were resuspended in RPMI 1640 medium supplemented with $2 \mathrm{mM}$ glutamine, $100 \mathrm{U} / \mathrm{ml}$ penicillin, $100 \mu \mathrm{g} / \mathrm{ml}$ streptomycin, and $10 \%$ FCS (v/v). The final concentration of neutrophils was $10^{6} / \mathrm{ml}$ in $200 \mu \mathrm{l}$ media. MalH-2 $(100 \mu \mathrm{M})$ was added $30 \mathrm{~min}$ before LPS $(30 \mu \mathrm{M}$, which induced a higher proinflammatory cytokine production) stimulation. After 4 and $12 \mathrm{~h}$, the supernatant was aspirated, centrifuged, and stored at $-70^{\circ} \mathrm{C}$.

Neutrophil depletion and reconstitution

Neutrophil depletion was accomplished with a rat, antimouse monoclonal antibody $(\mathrm{mAb})$ against the neutrophil maturation antigen, $\mathrm{Gr}-1$. The $\mathrm{Gr}-1 \mathrm{mAb}$ was purified from the RB6-8C5 hybridoma using standard methods. The Gr-1 $\mathrm{mAb}(160 \mu \mathrm{g})$ was given IP yielding greater than $90 \%$ neutrophil depletion at $24 \mathrm{~h}$ (data not shown). Before neutrophil-depleted mice were intratracheally challenged with LPS $(5 \mathrm{mg} / \mathrm{kg}), 6 \times 10^{6}$ freshly isolated bone marrow neutrophils were injected intravenously to reconstitute blood neutrophils as previously described [24, 26].

Bone marrow chimera experiments

As previously described, mice were lethally irradiated (6 Gy) and immediately reconstituted via retro-orbital injection with either WT or F508del bone marrow $\left(5 \times 10^{6}\right.$ cells) [27]. Mice were administered antibiotic-treated water for 3 weeks and then used for experiments at approximately 8 weeks after bone marrow transfer. Using this protocol, at 8 weeks after bone marrow transplantation, more than $90 \%$ of circulating hematopoietic cells are of donor origin.

Measurements of cytokine levels by ELISA

TNF- $\alpha$, MIP-2, and IL-10 in the BAL, supernatant of media, and plasma were measured by ELISA kits (TNF- $\alpha$, Endogen; MIP-2 and IL-10, R \& D Systems, http://www. rndsystems.com/).
Nuclear extraction and p65 NF- $\kappa$ B ELISA

Kits were purchased from Active Motif (Carlsbad, CA). Nuclear extraction and measurement of p65 NF- $\kappa \mathrm{B}$ were performed according to the manufacturer's instructions.

Detection of CFTR expression in neutrophils by immunofluorescence

We used standard methods for immunofluorescence as we have described previously [18]. The rabbit anti-CFTR polyclonal antibody (H-182, Santa Cruz Biotechnology) was used at a 1:200 dilution. The goat-anti-rabbit Cy3 labeled secondary antibody (Cy3, Sigma) were also used at a 1:200 dilution.

\section{Western blot for CFTR}

Total cellular protein was extracted from neutrophils. Fisher rat thyroid (FRT) cells expressing CFTR were used as a positive control. Denatured protein samples were run on a $4-12 \%$ gradient Bis-Tris gel (Invitrogen, Carlsbad, CA), with $40 \mu \mathrm{g}$ protein equal loading per lane, using a MOPS SDS buffer (Invitrogen) at $100 \mathrm{~V}$ for $1.5 \mathrm{~h}$. The proteins were then transferred to a nitrocellulose membrane and blocked with blocking buffer for $1 \mathrm{~h}$. The membrane was exposed to rabbit anti-CFTR polyclonal antibody (H-182, Santa Cruz Biotechnology) at 1:100 dilution overnight at $4{ }^{\circ} \mathrm{C}$. The blot was washed and then exposed to a HRP labeled antibody at 1:5,000 dilution for $45 \mathrm{~min}$. The protein bands were developed with an ECL kit (Amersham, Piscataway, NJ). The optical density of bands was analyzed using NIH image software.

\section{Quantitative PCR}

Gene expression in BAL cells and lung tissue was measured by a two-step multiplex RT-PCR method. Mouse cytokine and CFTR primers and probes were designed with "Primer Express" software (Perkin Elmer, Foster City, $\mathrm{CA}$ ); primer sequences were as follows:

\begin{tabular}{ll}
\hline M-MCP-1-RTF & TCTGGGCCTGCTGTTCACA \\
M-MCP-1-RTR & CCAGCCTACTCATTGGGATCA \\
M-MCP-1-TMF & GTTGGCTCAGCCAGATGCA \\
M-MCP-1-TMP & CGCCCCACTCACCTGCTGCTACTC \\
M-MCP-1-TMR & CCTACTCATTGGGATCATCTTGCT \\
M-MIP-2-RTF & TCAAGAACATCCAGAGCTTGAGTG \\
M-MIP-2-RTR & AACTTTTTGACCGCCCTTGAG \\
M-MIP-2-TMF & AGTGTGACGCCCCCAGG \\
M-MIP-2-TMP & CCCACTGCGCCCAGACAGAAGTCAT \\
\hline
\end{tabular}




\begin{tabular}{|c|c|}
\hline M-MIP-2-TMR & TTTGACCGCCCTTGAGAGTG \\
\hline M-IL- $1 \beta$-RTF & AGGCAGTATCACTCATTGTGGCT \\
\hline M-IL-1 $\beta$-RTR & TGAGTCACAGAGGATGGGCTC \\
\hline M-IL-1 $\beta$-TMF & AGAAGCTGTGGCAGCTACCTG \\
\hline M-IL-1 $\beta$-TMP & TCTTTCCCGTGGACCTTCCAGGATG \\
\hline M-IL-1 $\beta$-TMR & GGAAAAGAAGGTGCTCATGTCC \\
\hline M-TNF- $\alpha-\mathrm{RTF}$ & TGCTCAGAGCTTTCAACAACTACTC \\
\hline M-TNF- $\alpha-R T R$ & GAGGCTCCAGTGAATTCGGA \\
\hline M-TNF- $\alpha-T M F$ & GGACAGTGACCTGGACTGTGG \\
\hline M-TNF- $\alpha$-TMP & ССТСТСАTGCACCACCATCAAGGACTC \\
\hline M-TNF- $\alpha-T M R$ & AGTGAATTCGGAAAGCCCATT \\
\hline M-IFN $\gamma$-RTF & GCAACAGCAAGGCGAAAAAG \\
\hline M-IFN $\gamma$-RTR & AAAATTCAAATAGTGCTGGCAGAA \\
\hline M-IFN $\gamma$-TMF & AGCTCATCCGAGTGGTCCAC \\
\hline M-IFN $\gamma$-TMP & AGCTGTTGCCGGAATCCAGCCTC \\
\hline M-IFN $\gamma$-TMR & AGCAGCGACTCCTTTTCCG \\
\hline M-IL-13-RTF & TCGAAGTAGCCCACTTTATAACAAAA \\
\hline M-IL-13-RTR & GAAAATGAGTCCACAGCTGAGATG \\
\hline M-IL-13-TMF & ACTGCTCAGCTACACAAAGCAACT \\
\hline M-IL-13-TMP & TCGCCACGGCCCCTTCTAATGA \\
\hline M-TGF- $\beta 1-\mathrm{RTF}$ & CACCTGCAAGACCATCGACAT \\
\hline M-TGF- $\beta 1-$ RTR & GGGACTGGCGAGCCTTAGTT \\
\hline M-TGF- $\beta 1$-TMF & AAACGGAAGCGCATCGAA \\
\hline M-TGF- $\beta 1$-TMP & CCATCCGTGGCCAGATCCTGTCC \\
\hline M-TGF- $\beta 1-T M R$ & GGGACTGGCGAGCCTTAGTT \\
\hline M-CFTR-RTF & CGACTCCCTTCAGGCACTTC \\
\hline M-CFTR-RTR & ATTTGCGTCCGAGGCTTGT \\
\hline M-CFTR-TMF & TATCTTCCAGCAGGCCATTAGC \\
\hline M-CFTR-TMP & TTCTTCCAGGGCCGCCACTCC \\
\hline M-CFTR-TMR & ATTTGCGTCCGAGGCTTGT \\
\hline
\end{tabular}

Total RNA (10-20 ng) was reverse transcribed with random hexamers, and the resulting cDNA product was amplified using a mix of gene-specific primers and hot-start PCR for 25 cycles. Transcript quantifications were run along with -RT cDNA controls in a 384-well format on an ABI Prizm 7900 Sequence Detection System (Applied Biosystems, Foster City, CA). Data were collected as PCR cycle threshold values for each gene and then converted to relative gene copy numbers (GCN) based on linear regression as previously described. Transcript copy was normalized using a panel of ten housekeeping genes.

Statistical analysis

Statistics were done using SPSS software (SPSS, Chicago, IL) and results are presented as mean \pm SD. One-way analysis of variance (ANOVA) with post hoc Bonferroni test or Student's $t$ test were used as appropriate (level set at $P<0.05)$. Area under curve was calculated using Trapezoid Rule, Method 1.
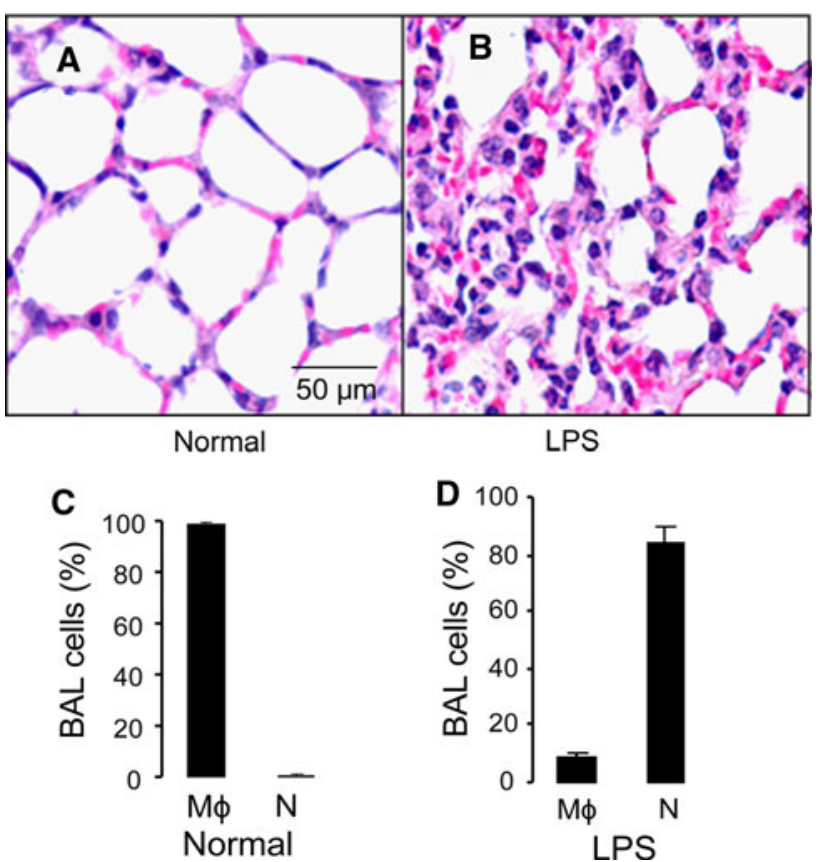

Fig. 1 Histology of the lung and BAL inflammatory cells. a, b Histology of normal (a) and lipopolysaccharide (LPS) injured (b) lung (H-E staining, objective magnification $\times 40$, bar $50 \mu \mathrm{m}$ ). c, $\mathbf{d}$ Percentage of alveolar macrophages and neutrophils in BAL cells under normal conditions and LPS-induced acute lung injury (d) at 24 h. $M \Phi$ Alveolar macrophages, $N$ neutrophils

\section{Results}

CFTR mRNA expression is upregulated in BAL inflammatory cells from LPS-injured lungs

To study the effect of LPS-induced lung inflammation on CFTR mRNA expression, we collected lung tissue and BAL cells separately $24 \mathrm{~h}$ after wild-type mice were challenged intratracheally with either PBS or LPS $(5 \mathrm{mg} /$ $\mathrm{kg}$ ). Histologically, LPS-injured lungs displayed pulmonary edema, neutrophil infiltration, and hemorrhage (Fig. 1a, b) and the mRNA of cytokines (MCP-1, MIP-2, IL-1 $\beta$, and TNF- $\alpha$ ) increased 75, 1,029, 30, and 30-fold respectively (Table 1). Gene transcripts of CFTR were detected, but there was no difference between the PBS control and LPSchallenged lung tissue (Table 1). In the BAL inflammatory cells, LPS challenge switched the cell population from alveolar macrophages to predominantly neutrophils (Fig. 1c, d) and the mRNA of several cytokines (MCP-1, MIP-2, IL- $1 \beta$, and TNF- $\alpha$ ) in the BAL cells increased, by 35, 494, 93, and 18.9-fold respectively $(P<0.01$, Table 2). The mRNA for CFTR in the inflammatory cells was elevated three-fold after LPS challenge $(P<0.05$, Table 2). These data suggest that the acute inflammatory cells (mainly neutrophils in the BAL) that respond to 
Table 1 Alterations of mRNA expression of cytokines and cystic fibrosis transmembrane conductance regulator (CFTR) in normal versus LPS-injured lung

\begin{tabular}{|c|c|c|c|c|}
\hline & \multicolumn{2}{|c|}{ Gene copy numbers (mean \pm SD) } & \multirow[t]{2}{*}{$P$ values } & \multirow[t]{2}{*}{ Fold } \\
\hline & Normal & LPS-injured & & \\
\hline MCP-1 & $20,092 \pm 4,965$ & $1,512,494 \pm 233,280$ & 0.0036 & 75 \\
\hline MIP-2 & $12,777 \pm 2,692$ & $13,151,494 \pm 664,219$ & 0.001 & 1,029 \\
\hline IL-1 $\beta$ & $268,455 \pm 60,329$ & $8,068,521 \pm 2,334,069$ & $7.35 \times 10^{5}$ & 30 \\
\hline TNF- $\alpha$ & $16,061 \pm 8,063$ & $484,725 \pm 143,663$ & $8.5 \times 10^{5}$ & 30 \\
\hline $\mathrm{IFN}-\gamma$ & $3,474 \pm 1,736$ & $9,277 \pm 4,422$ & 0.025 & 2.67 \\
\hline IL-13 & $1,252 \pm 650$ & $2,553 \pm 1,124$ & 0.055 & 2 \\
\hline TGF- $\beta 1$ & $1,043,985 \pm 72,726$ & $847,249 \pm 95,611$ & 0.006 & 0.86 \\
\hline CFTR & $276,351 \pm 32,068$ & $238,070 \pm 55,057$ & 0.21 & 0.81 \\
\hline
\end{tabular}

LPS-induced lung inflammation and injury are able to upregulate CFTR transcripts.

CFTR protein expression is upregulated in neutrophils under LPS stimulation

To study whether neutrophils express CFTR, we isolated mouse bone marrow neutrophils. The purity of isolated neutrophils was more than $92 \%[24,26]$. These bonemarrow derived neutrophils express CFTR (Fig. 2a, b). To study whether activated neutrophils express CFTR, BAL cells were isolated $24 \mathrm{~h}$ after mice were challenged intratracheally with LPS $(5 \mathrm{mg} / \mathrm{kg})$. Neutrophils comprised $84 \pm 6 \%$ of the BAL cell population (Fig. 1d) and these neutrophils were also positively stained by anti-CFTR antibody (Fig. 2c, d). To test whether CFTR protein expression in neutrophils would be altered upon LPS challenge, we cultured bone marrow neutrophils and stimulated them with either PBS or LPS $(30 \mu \mathrm{M})$. After $24 \mathrm{~h}$, an equal amount of protein from the cell lysates was used for Western blot analysis. As a positive control, we used FRT cells that express high amounts of CFTR with a molecular weight $170 \mathrm{kDa}$ to demonstrate the specificity of the anti-CFTR antibody (H-182). LPS-stimulated neutrophils also displayed a more intense $170 \mathrm{kD}$ band, and the optical density of the band was increased compared to the PBS-stimulated group $(P<0.05$, Fig. 2 e) .

Inhibition of CFTR in neutrophils with MalH-2 increases the production of NF- $\kappa \mathrm{B}$ dependent proinflammatory cytokines

To test whether inhibition of CFTR in neutrophils would increase proinflammatory cytokine production, we cultured isolated wild-type bone marrow neutrophils for $4 \mathrm{~h}$ and measured two important pro-inflammatory cytokines/chemokines-TNF- $\alpha$ and MIP-2 -in the medium supernatant. In LPS-stimulated bone marrow neutrophils, both TNF- $\alpha$ and MIP-2 production were increased, and inhibition of CFTR with MalH-2 further increased TNF- $\alpha$ and MIP-2 production (Fig. 3a, b). At $12 \mathrm{~h}$, MalH-2 significantly increased MIP-2 production in LPS-stimulated wild-type neutrophils compared to LPS only (Fig. 3c). For confirmation, we used F508del neutrophils as a positive control. At $12 \mathrm{~h}$, MIP-2 levels in F508del neutrophils stimulated with LPS were increased by three-fold compared to the wild-type neutrophils stimulated with LPS (Fig. 3c), suggesting that CFTR is a modulator of proinflammatory cytokines in bone marrow neutrophils. To investigate whether CFTR inhibition induced excessive MIP-2

Table 2 Alterations of mRNA expression of cytokines and CFTR in normal versus LPS-challenged BAL cells

\begin{tabular}{lcccc}
\hline & \multicolumn{2}{c}{ Gene copy numbers $($ mean \pm SD) } & & $P$ values \\
\cline { 2 - 4 } & Normal & LPS-injured & 0.00149 \\
\hline MCP-1 & $3,560 \pm 5,209$ & $125,365 \pm 61,329$ & 35 \\
MIP-2 & $93,277 \pm 14,194$ & $46,077,687 \pm 15,286,520$ & 0.000304 \\
IL-1 $\beta$ & $319,310 \pm 125,384$ & $29,646,533 \pm 2,233,126$ & 0.00209 \\
TNF- $\alpha$ & $90,512 \pm 71,027$ & $1,711,051 \pm 150,834$ & $1.99 \times 10^{9}$ & Nold \\
IFN- $\gamma$ & 304 & $3,628 \pm 1,726$ & 0.30771 \\
IL-13 & $101 \pm 31$ & $384 \pm 333$ & 0.000138 \\
TGF- $\beta 1$ & $2,063,179 \pm 56,175$ & $1,536,760 \pm 163,824$ & 0.04258 \\
CFTR & $1,006 \pm 676$ & $3,484 \pm 1,809$ & 3.8 \\
\hline
\end{tabular}




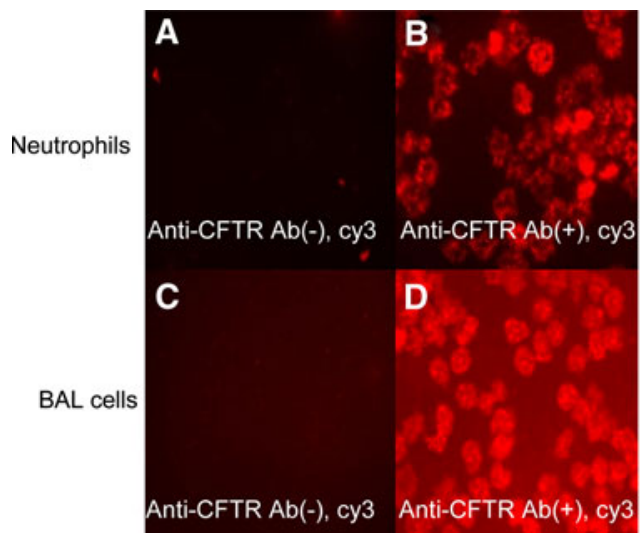

Fig. 2 Detection of CFTR by immunofluorescence and Western blot in mouse BAL and bone marrow neutrophils. a, b CFTR immunofluorescence in naïve neutrophils and LPS-stimulated neutrophils. a The 2nd antibody was labeled with Cy 3 without primary antibody. b The 2nd antibody was labeled with Cy3 with primary anti-CFTR antibody. c, $\mathbf{d}$ Detection of CFTR in BAL cells. $\mathbf{c}$ The 2nd antibody was labeled with $\mathrm{Cy} 3$ without primary antibody. $\mathbf{d}$ The 2 nd antibody

production in neutrophils through an NF- $\kappa$ B pathway, LPS simulated wild-type neutrophils were pretreated either with BMS-345541 (50 $\mu \mathrm{M}$, which was chosen to reach maximal inhibitory effects on NF- $\kappa \mathrm{B}$ in neutrophils) or BMS$345541+$ MalH-2. BMS-345541 pretreated neutrophils stimulated with LPS produced less MIP-2 compared to LPS alone. BMS-345541 also completely inhibited excessive MIP-2 production in the LPS-stimulated neutrophils with MalH-2 pretreatment (Fig. 3d), suggesting that CFTR regulates MIP-2 production through the NF- $\kappa$ B pathway in LPS-stimulated bone marrow neutrophils.

Lack of functional CFTR in neutrophils contributes to inflammatory imbalance and promotes NF- $\kappa \mathrm{B}$ translocation

To study whether lack of functional CFTR in neutrophils affects both pro- and anti-inflammatory cytokines, isolated bone marrow neutrophils were pretreated with $\mathrm{CFTR}_{\text {inh }^{-}}$ $172(5 \mu \mathrm{M})$, stimulated with LPS, and cultured for $12 \mathrm{~h}$ to measure MIP-2 and IL-10 in the medium. The adherent neutrophils were then harvested for measurement of p65 $\mathrm{NF}-\kappa \mathrm{B}$ subunit in nuclear extract; MIP-2 levels increased more than two-fold (Fig. 4a) and IL-10 was significantly decreased (Fig. $4 \mathrm{~b}$ ) in the medium. The p65 NF- $\kappa$ B subunit in the neutrophil nucleus extract with LPS plus CFTRinh172 inhibition was increased two-fold compared to LPS only (Fig. 4c). To confirm this result, F508del and wildtype neutrophils were cultured and stimulated with LPS for $12 \mathrm{~h}$ to measure MIP-2 and IL-10 in the medium. The cells were then harvested for measurement of $\mathrm{p} 65 \mathrm{NF}-\kappa \mathrm{B}$ in the nucleus. MIP-2 levels were elevated three-fold (Fig. 4d)
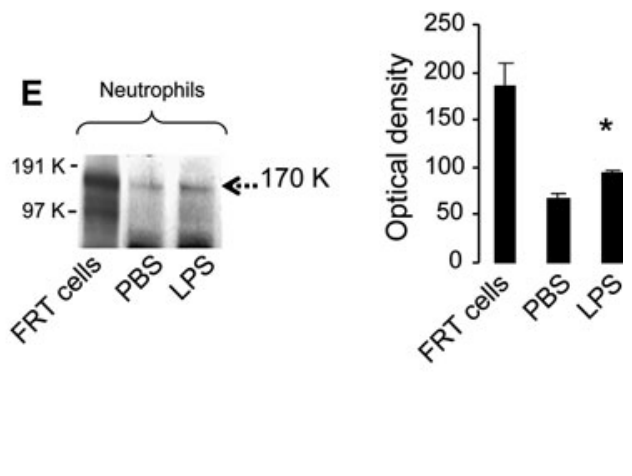

was labeled with Cy3 with primary anti-CFTR antibody. Experiments were repeated three times. e Western blot for CFTR in neutrophils and optical density of bands. Lanes (left to right): 1 FRT cells, 2 bonemarrow neutrophils with PBS, 3 bone-marrow neutrophils with LPS stimulation. ${ }^{*} P<0.05$ for LPS-stimulated neutrophils versus PBStreated neutrophils; experiments were repeated twice

and IL-10 was reduced (Fig. 4e). There was increased p65 $\mathrm{NF}-\kappa \mathrm{B}$ translocation to the nucleus in the F508del neutrophils stimulated with LPS compared to wild-type neutrophils receiving LPS challenge (Fig. 4f).

Lack of functional CFTR increases lung vascular permeability and promotes neutrophil chemotaxis and NF- $\kappa \mathrm{B}$ translocation in LPS-induced acute lung injury

To test the effect of CFTR inhibition in the airspaces of the lung in vivo, the CFTR inhibitor-MalH-2 $(2 \mathrm{mg} / \mathrm{kg})$ was instilled intratracheally into the airspaces of the lung $20 \mathrm{~min}$ prior to LPS challenge $(5 \mathrm{mg} / \mathrm{kg}$ ) or PBS (control). Four hours later, protein concentration in the BAL (an index of lung vascular permeability) in the MalH-2 pretreated group was increased (Fig. 5a). MalH-2 alone did not show any effects on the parameters that we measured compared to vehicle (data not shown). There was a trend for an elevation of leukocyte and neutrophil counts in the BAL in the MalH-2 pretreated/LPS treated group at this early $4 \mathrm{~h}$ time point (Fig. 5b, c). For confirmation, wildtype and F508del mice were challenged intratracheally with LPS $(5 \mathrm{mg} / \mathrm{kg})$. Four hours later, BAL protein, leukocyte and neutrophil counts in F508del mice were increased compared to the wild-type mice (Fig. 5d-f). Additionally, wild-type and F508del mice were challenged intratracheally with LPS $(5 \mathrm{mg} / \mathrm{kg})$ and sacrificed at 1 and $4 \mathrm{~h}$ to collect BAL cells and to measure p65 NF- $\kappa \mathrm{B}$ activity. The $\mathrm{p} 65 \mathrm{NF}-\kappa \mathrm{B}$ subunit was increased in the nuclei of F508del BAL inflammatory cells at 1 and $4 \mathrm{~h}$ compared to the wild-type BAL cells (Fig. $5 \mathrm{~g}$, h). 

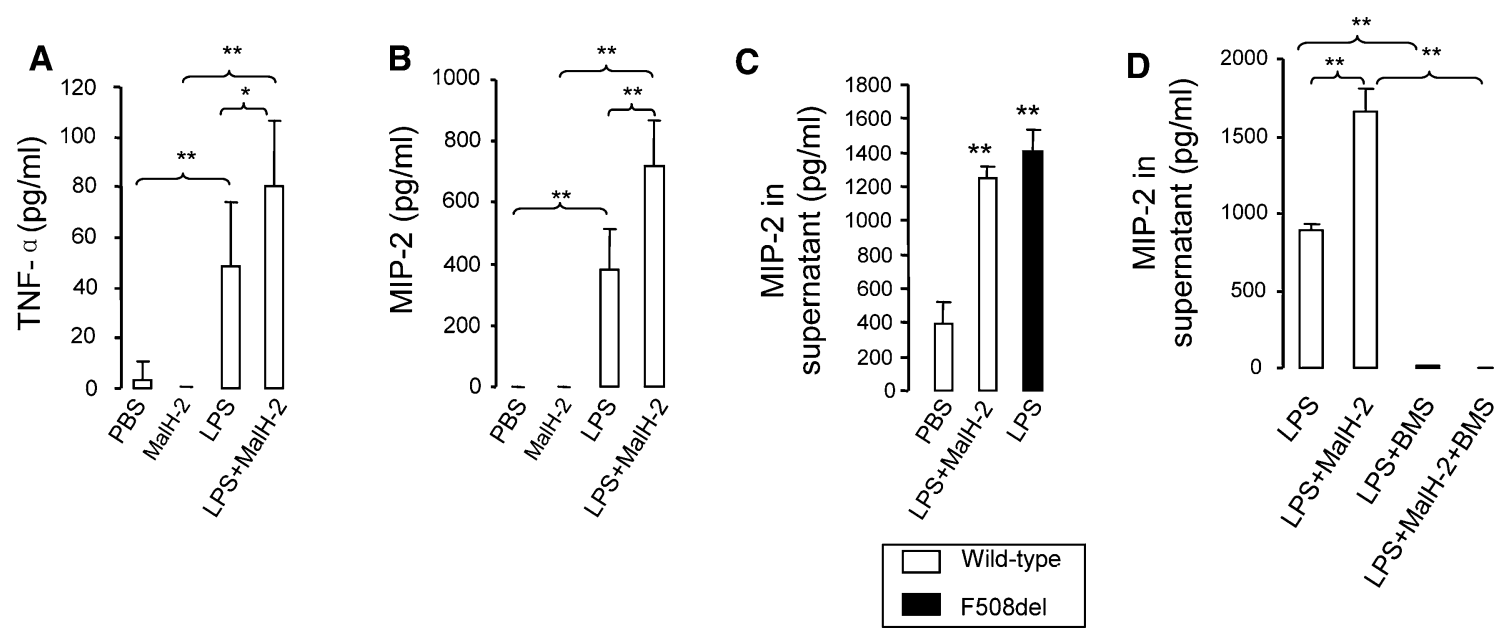

Fig. 3 Pharmacologic inhibition or mutation of CFTR neutrophils affects proinflammatory cytokine production and NF- $\kappa \mathrm{B}$ activation. $\mathbf{a}, \mathbf{b}$ Cytokine levels in the supernatant of cultured neutrophils at $4 \mathrm{~h}$. a TNF- $\alpha$. b MIP-2. $* P<0.05$ for LPS vs LPS + MalH-2; $* * P<0.01$ vs PBS or MalH-2 only. c MIP-2 levels in the supernatant of cultured neutrophils stimulated with LPS at $12 \mathrm{~h}$. $* * P<0.01$ for

wild-type neutrophils receiving MalH-2 or F508del neutrophils stimulated with LPS vs LPS only. d Effect of inhibition of NF- $\kappa$ B on production of MIP-2 in wild-type neutrophils with CFTR inhibition by MalH-2. $* * P<0.01$ for LPS vs LPS + MalH-2; \#\# $P<0.01$ for LPS vs LPS MalH-2 + BMS-34553. $N=6-8$ in each group. Values are mean $\pm \mathrm{SD}$

Fig. 4 Pro- and anti-

inflammatory cytokines in neutrophils balance is impaired without functional CFTR. a-c Production of MIP-2 (a) and interleukin-10 (b) and $\mathrm{NF}-\kappa \mathrm{B}$ activation $(\mathbf{c})$ in the cultured bone-marrow derived wild-type neutrophils pretreated with CFTR $_{\text {inh }^{-172} \text { and then }}$ stimulated with LPS at $12 \mathrm{~h}$. $* * P<0.01$ for

LPS + CFTR $_{\text {inh }}-172$ vs LPS only. d-f Production of MIP-2 (d) and interleukin-10 (e) and NF- $\kappa$ B activation (f) in the cultured bone-marrow derived wild-type neutrophils and F508del neutrophils simulated with LPS at $12 \mathrm{~h}$. $* P<0.05$, $* * P<0.01$ for wild-type neutrophils receiving LPS vs F508del neutrophils stimulated with LPS. $N=6-8$ in each group. Values are mean $\pm \mathrm{SD}$
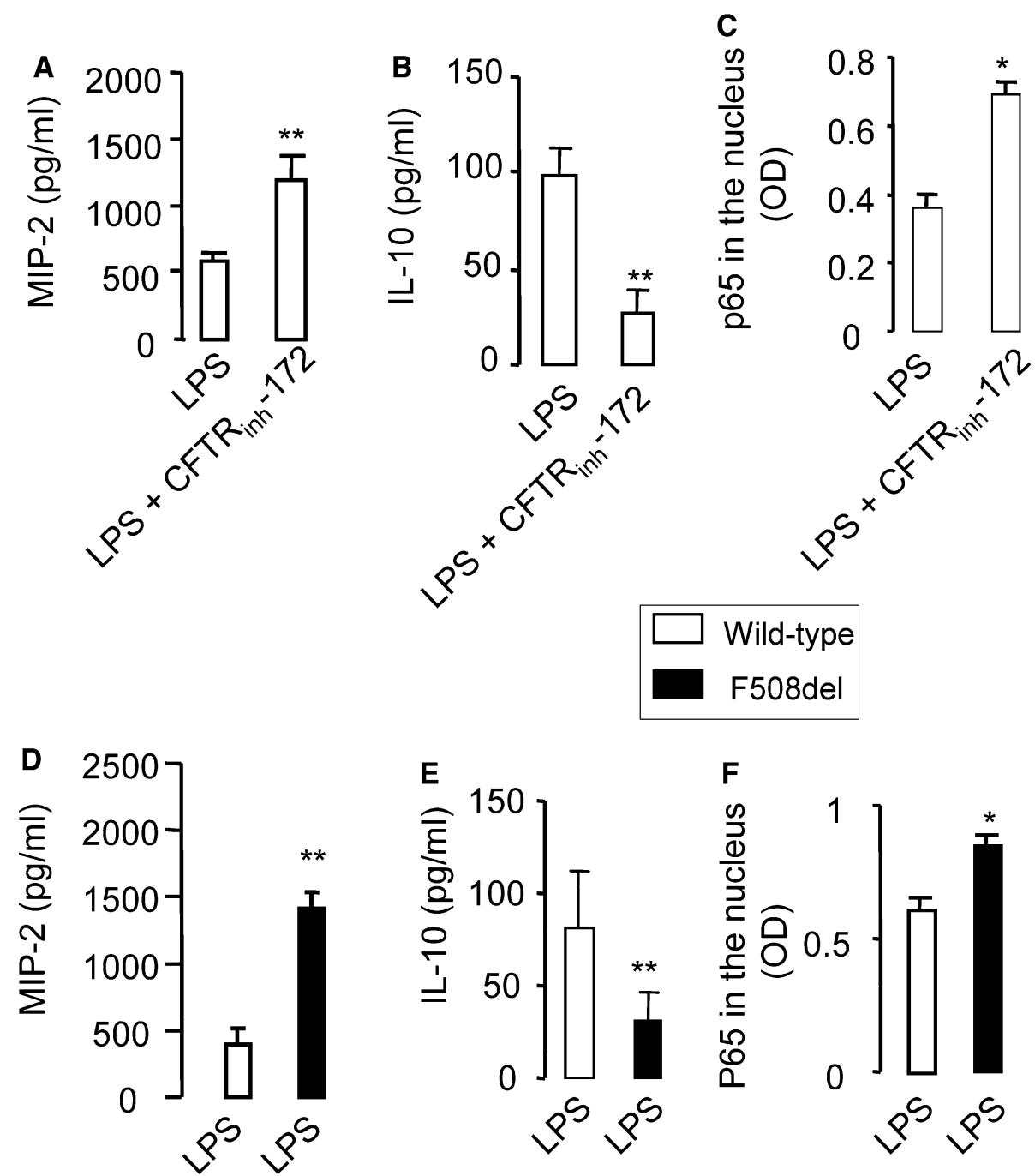

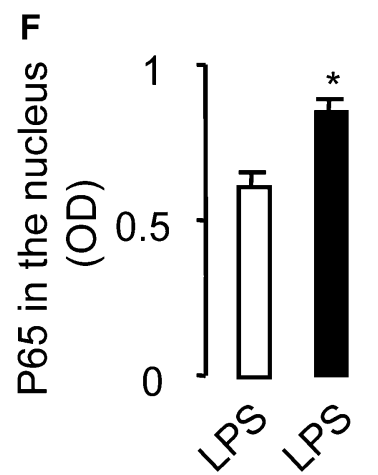


Fig. 5 In vivo effects of intratracheal CFTR pharmacologic inhibition in mice challenged with LPS. ac MalH-2 inhibition at $4 \mathrm{~h}$ : a BAL protein, $\mathbf{b} \mathrm{BAL}$ leukocytes, c BAL neutrophils; $N=5$ per group. d-f F508del mice at $4 \mathrm{~h}$ : d BAL protein, e BAL leukocytes, $\mathbf{f}$ BAL neutrophils; $N=10$ per group. $\mathbf{g}, \mathbf{h}$ p65 NF- $\kappa \mathrm{B}$ activity in the nucleus of BAL inflammatory cells from wild-type and F508del mice at $1 \mathrm{~h} \mathrm{(g)} \mathrm{and} 4 \mathrm{~h}$ (h); $N=5$ per group. Values are mean $\pm \mathrm{SD}$
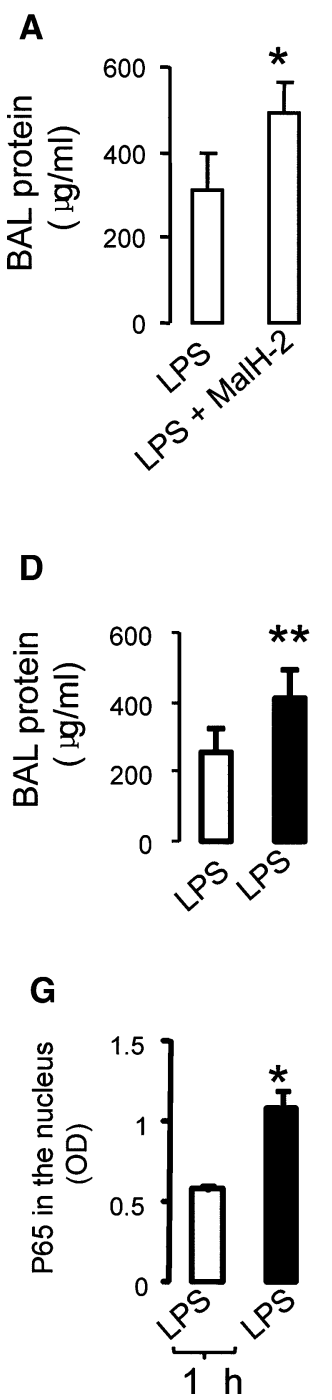

Inhibition of CFTR with systemic administration of MalH-2 worsens LPS-induced acute lung injury

To test whether systemic administration of a CFTR inhibitor would amplify pulmonary and systemic inflammatory responses to endotoxin challenge, mice received an intratracheal instillation of LPS $(5 \mathrm{mg} / \mathrm{kg})$ after CFTR inhibition with MalH-2 (3 mg/kg, every $12 \mathrm{~h}$, ip; this dosage of MalH-2 itself did not cause any toxicity to the mice). The first MalH-2 injection was given 20 min prior to IT LPS or PBS (control). At $24 \mathrm{~h}$, extravascular lung water (an index of pulmonary edema) was increased in the MalH2 treated group (Fig. 6a). The mice receiving MalH-2 and LPS developed systemic neutrophilia (higher neutrophil counts in the blood) and hypothermia (a sign of the systemic inflammatory response) (Fig. 6b, c). Lung and BAL MIP-2 levels, and MPO (an index of neutrophil infiltration) were increased in the LPS + MalH-2 group at $24 \mathrm{~h}$ compared to the LPS only group (Fig. 6d-f). At 48 h, MIP-2
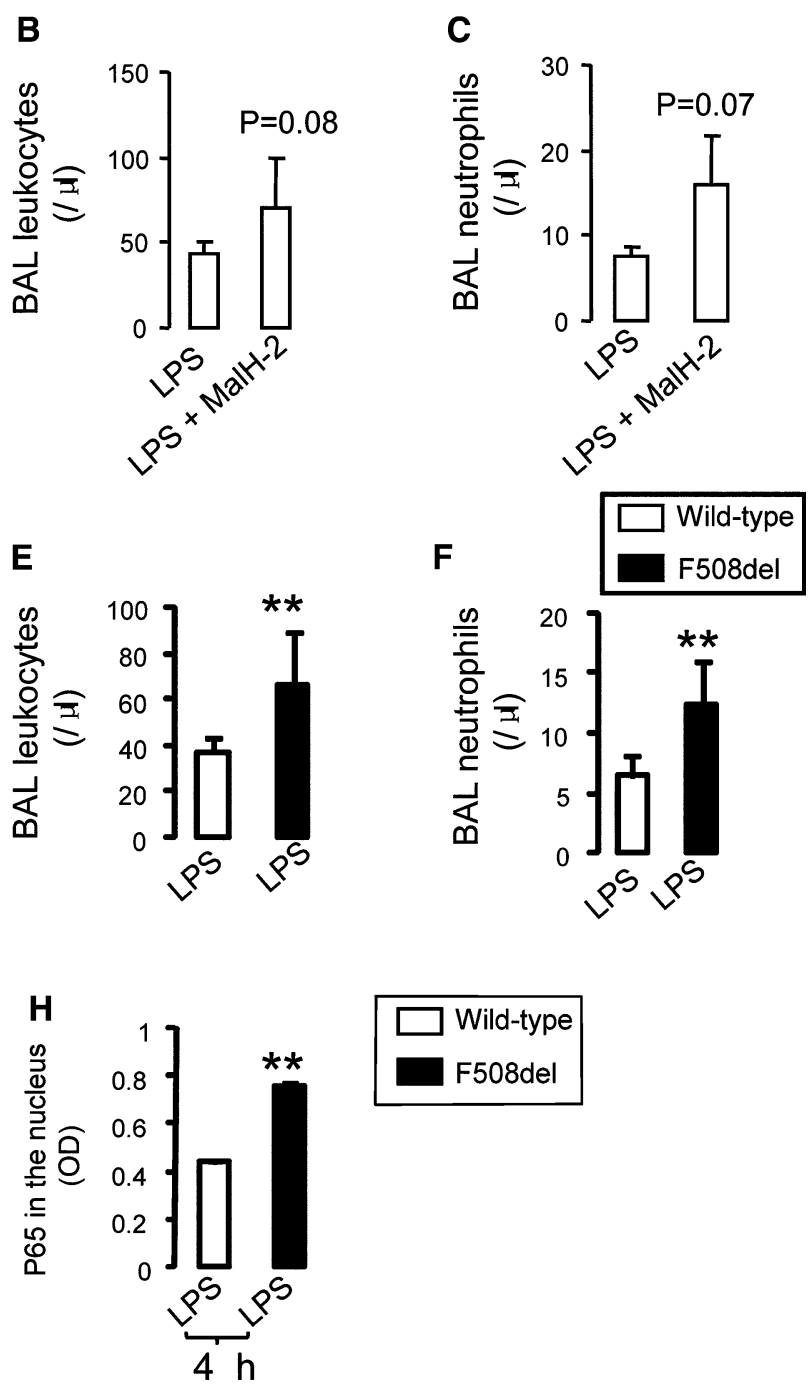

levels and MPO activity in the supernatant of the liver homogenate were also increased with CFTR inhibition (Fig. 6g, h).

LPS-induced acute lung injury is amplified in F508del mice

To determine if the lack of functional CFTR worsens acute lung injury, wild-type and F508del mice were challenged intratracheally with LPS $(5 \mathrm{mg} / \mathrm{kg})$. At $24 \mathrm{~h}$, extravascular lung water and BAL total protein were higher in the F508del mice that received intratracheal LPS compared to wild-type mice that received intratracheal LPS (Fig. 7a, b). After LPS challenge in the F508del mice, there was more neutrophil recruitment into the airspaces (Fig. 7c) and more systemic neutrophilia (Fig. 7d). There was also an amplified proinflammatory state in the lung (higher BAL MIP-2 and TNF- $\alpha$, Fig. 7e, f) and systemically (increased plasma MIP-2 and TNF- $\alpha$, Fig. 7g, h). Additionally, at 
Fig. 6 CFTR pharmacologic inhibition with MalH-2 worsens LPS-induced acute lung injury water. b Blood neutrophils. c Body temperature. d MIP-2 levels in the supernatant of lung homogenate. e MPO activity in the lung homogenate. $f$ BAL the supernatant of liver homogenate. $\mathbf{h}$ MPO activity in the liver homogenate. $* P<0.05$ or $* * P<0.01$ for LPS + MalH-2 vs LPS only. $N=5-6$, in each group. Values are mean $\pm \mathrm{SD}$ at $24 \mathrm{~h}$. a Extravascular lung MIP-2 levels. g MIP-2 levels in
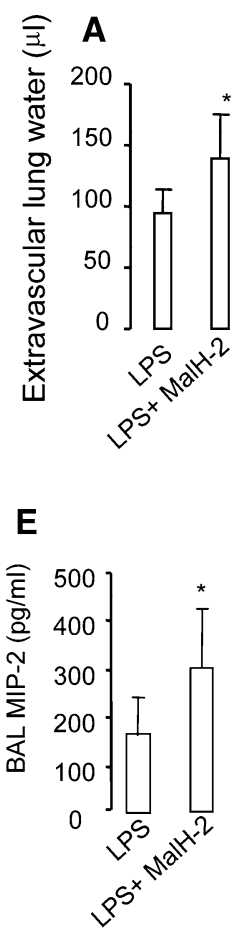

$24 \mathrm{~h}, \mathrm{p} 65 \mathrm{NK}-\kappa \mathrm{B}$ activity in the nucleus was greater in the BAL inflammatory cells from F508del mice (Fig. 7i).

F508del bone marrow contributes to lung inflammation and injury

To isolate the effects of CFTR dysfunction in vivo, we created bone marrow chimeras using wild-type and F508del mice. Two months after bone marrow transplantation, WT/WT (wild-type mice receiving wild-type bone marrow), WT/F508del (wild-type mice receiving F508del bone marrow), F508del/WT (F508del mice receiving wildtype bone marrow), and F508del/F508del mice (F508del recipient receiving F508del bone marrow) were challenged intratracheally with LPS. At $24 \mathrm{~h}$ after LPS, BAL MPO and protein levels were elevated in all groups compared to the WT/WT group (Fig. 8a-c). Higher MIP-2 production was also found in the airspaces of the WT/F508del group and F508del/F508del groups compared to the WT/WT group (Fig. 8c).

F508del neutrophils contribute to lung inflammation and injury

Since F508del bone marrow increases lung inflammation and injury, we next conducted experiments on the specific role of F508del neutrophils. We depleted neutrophils from wild-type mice and replaced them with F508del neutrophils $\left(6 \times 10^{6} /\right.$ mouse, IV), and then challenged these mice with LPS $(5 \mathrm{mg} / \mathrm{kg})$ intratracheally. We also studied
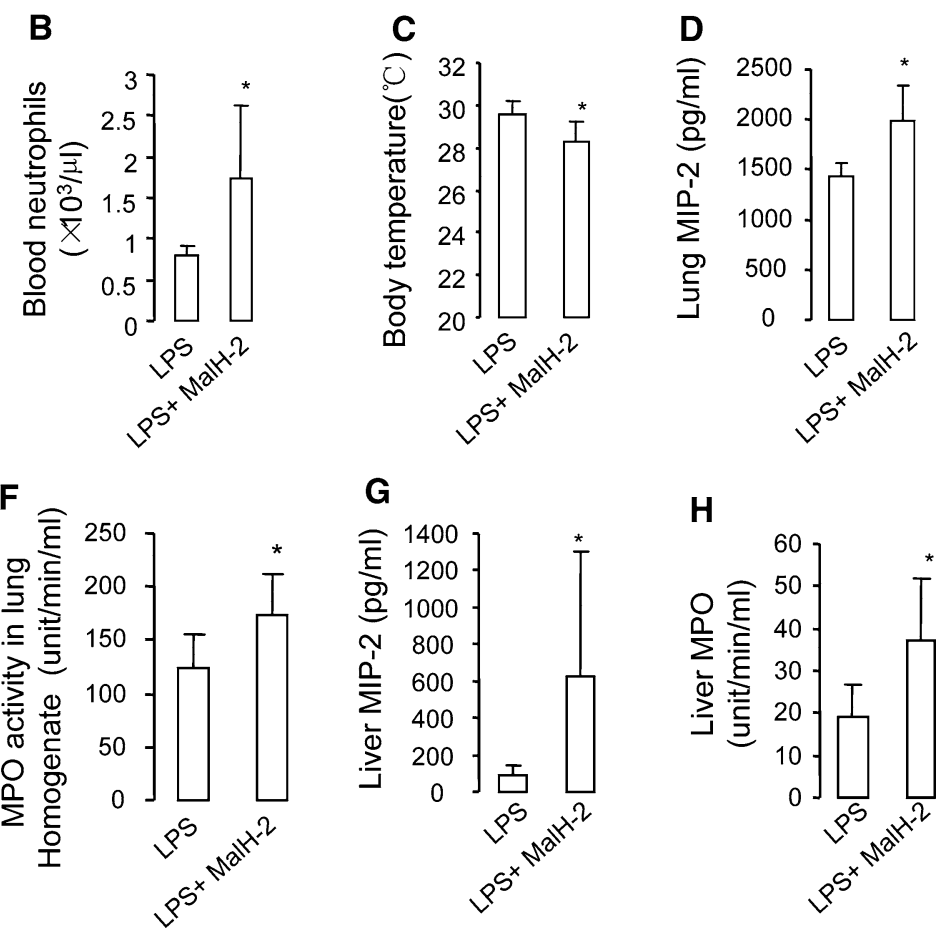

neutrophil-depleted wild-type mice that received donor wild-type neutrophils and neutrophil-depleted F508del mice that received donor F508del neutrophils. At $4 \mathrm{~h}$ after LPS challenge, BAL neutrophils were increased in neutrophil-depleted F508del mice that received donor F508del neutrophils (Fig. 9a) compared to neutrophil-depleted wild-type mice that received donor wild-type neutrophils, which re-established the phenotype shown in Fig. 5f. At $24 \mathrm{~h}$, extravascular lung water was increased in neutrophil-depleted F508del mice that received donor F508del neutrophils (Fig. 9d) compared to neutrophil-depleted wild-type mice that received donor wild-type neutrophils, which was also the phenotype of the mice in Fig. 7a. Most importantly, reconstitution of neutrophil-depleted wildtype mice with F508del neutrophils promoted neutrophil recruitment into the airspaces of the lung, increased MIP-2 and TNF- $\alpha$ levels in the BAL (Fig. 9b, c) at $4 \mathrm{~h}$, and worsened extravascular lung water (Fig. 9d) compared to neutrophil-depleted wild-type mice receiving wild-type neutrophils at $24 \mathrm{~h}$.

\section{Discussion}

Using both pharmacologic inhibition and mutation (F508del) of CFTR, we provide evidence that lack of functional CFTR in neutrophils propagates production of $\mathrm{NF}-\kappa \mathrm{B}$-dependent proinflammatory cytokines and worsens LPS-induced acute lung inflammation and injury. We also found that CFTR-mutated neutrophils are more 

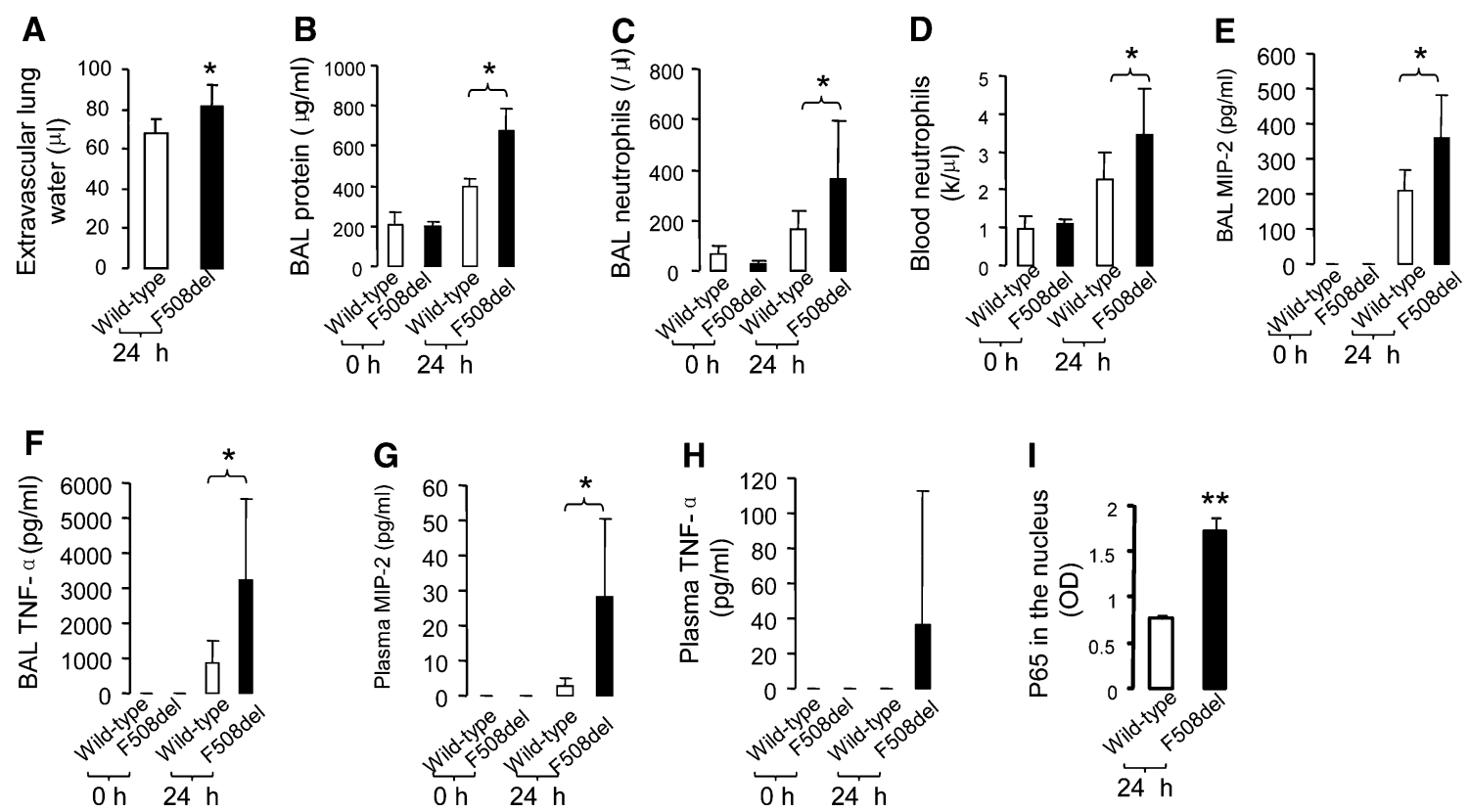

Fig. 7 Lack of functional CFTR worsens LPS-induced acute lung injury in mice. a, b Extravascular lung water and BAL protein at $24 \mathrm{~h}$ after wild-type and F508del mice were challenged intratracheally with LPS; $N=5$ per group, ${ }^{*} P<0.05$ or $P<0.01$ for F508del vs wild-type mice. $\mathbf{c}, \mathbf{d}$ Mutation of CFTR alters BAL neutrophil count, and blood neutrophil counts at $24 \mathrm{~h}$ after intratracheal LPS; $N=5$ at $0,24 \mathrm{~h}$ in each group, ${ }^{*} P<0.05$ for F508del vs wild-type mice at $24 \mathrm{~h}$. e, f Mutation of CFTR affect BAL MIP-2 and TNF- $\alpha$ at $24 \mathrm{~h}$ between wild-type and F508del mice with intratracheal LPS: e BAL

inflammatory than wild-type neutrophils and amplify lung inflammation and injury in response to LPS challenge.

It has been reported that human neutrophils express CFTR [10]. In this study, we also found that mouse neutrophils expressed CFTR as confirmed by immunofluorescence, gene transcript, and protein analysis. More importantly, for the first time, we found that CFTR expression in neutrophils was upregulated at the transcript and protein level after LPS challenge. In a LPS-induced acute lung injury mouse model, CFTR expression in BAL cells (predominated by neutrophils) was also increased by threefold. Inhibition or mutation of CFTR promotes NF- $\kappa$ B p65 translocation from the cytoplasm to the nucleus in LPS-stimulated neutrophils, suggesting that activation of CFTR might counteract NF- $\kappa$ B activation and limit proinflammatory responses in the neutrophils. Lack of functional CFTR could result in excessive NF- $\kappa \mathrm{B}$ activation in neutrophils and therefore propagate a hyper-inflammatory response.

Neutrophils can be mobilized from the bone marrow and recruited into the airspaces of the lung after intratracheal LPS challenge [28, 29]. If CFTR-deficient neutrophils are recruited into the lung, the proinflammatory state in response to acute infection may be amplified [30, 31]. TNF- $\alpha$ and MIP-2 play important roles in mobilizing
MIP-2, $\mathbf{f}$ BAL TNF- $\alpha . \mathbf{g}, \mathbf{h}$ Effect of mutation of CFTR on plasma MIP-2 and TNF- $\alpha$ at $24 \mathrm{~h}$ in wild-type and F508del mice with intratracheal LPS. $N=5$ at $0,24 \mathrm{~h}$ in each group, $* P<0.05$ for F508del vs wild-type mice at $24 \mathrm{~h}$. i p $65 \mathrm{NF}-\kappa \mathrm{B}$ in the nuclei of BAL inflammatory cells (including alveolar macrophages and neutrophils) harvested from wild-type and F508del mice after intratracheal instillation with LPS. $N=5$ in each group, $* P<0.05$ for F508del vs wild-type mice. Values are mean $\pm \mathrm{SD}$

neutrophils and promoting LPS-induced acute lung inflammation $[32,33]$. In the present study, inhibition and mutation of CFTR facilitated production of proinflammatory cytokines (TNF- $\alpha$ and MIP-2) in the BAL and promoted neutrophil alveolar translocation and p65 NF- $\kappa \mathrm{B}$ translocation in the BAL cells (predominantly neutrophils). Our results suggest that, under inhibition or mutation, the infiltrated neutrophils in the airspaces of the lung can be activated by LPS or bacterial challenge to produce more $\mathrm{NF}-\kappa \mathrm{B}$ dependent proinflammatory cytokines and worsen pulmonary inflammation. These results provide evidence to support the hypothesis that the lack of functional CFTR in neutrophils promotes proinflammatory responses, which facilitate the development of sepsis-induced acute lung inflammation and injury. In addition, lack of functional CFTR in neutrophils also reduced production of the antiinflammatory cytokine, IL-10 [34], suggesting that CFTR might also regulate the anti-inflammatory responses in LPS-challenged neutrophils.

We also conducted experiments with neutrophil or bone marrow reconstitution to confirm that the lack of functional CFTR in neutrophils promotes LPS-induced acute lung inflammation and injury. Under LPS challenge, neutrophildepleted wild-type mice reconstituted with F508del 
Fig. 8 Greater neutrophil transmigration, higher epithelial and vascular permeability, and chemokine production in the wild-type mice receiving F508del bone marrow transplantation and intratracheal LPS challenge. a BAL myeloperoxidase (MPO) using a kinetic assay. $* P<0.05$ for WT/WT vs WT/F508del, F508del/WT, and F508del/ F508del group. b Comparison of MPO levels in the BAL by calculating area under curve to confirm the significant differences between WT/WT and the other groups. c BAL protein levels. $P<0.05$ or 0.01 for WT/WT vs WT/F508del, F508del/WT, and F508del/ F508del group. d BAL MIP-2 levels. $P<0.05$ or 0.01 for WT/ WT vs WT/F508del, and F508del/F508del group. Data were pooled from at least three independent experiments.

$N=4-6$ in each group. Values are mean $\pm \mathrm{SD}$
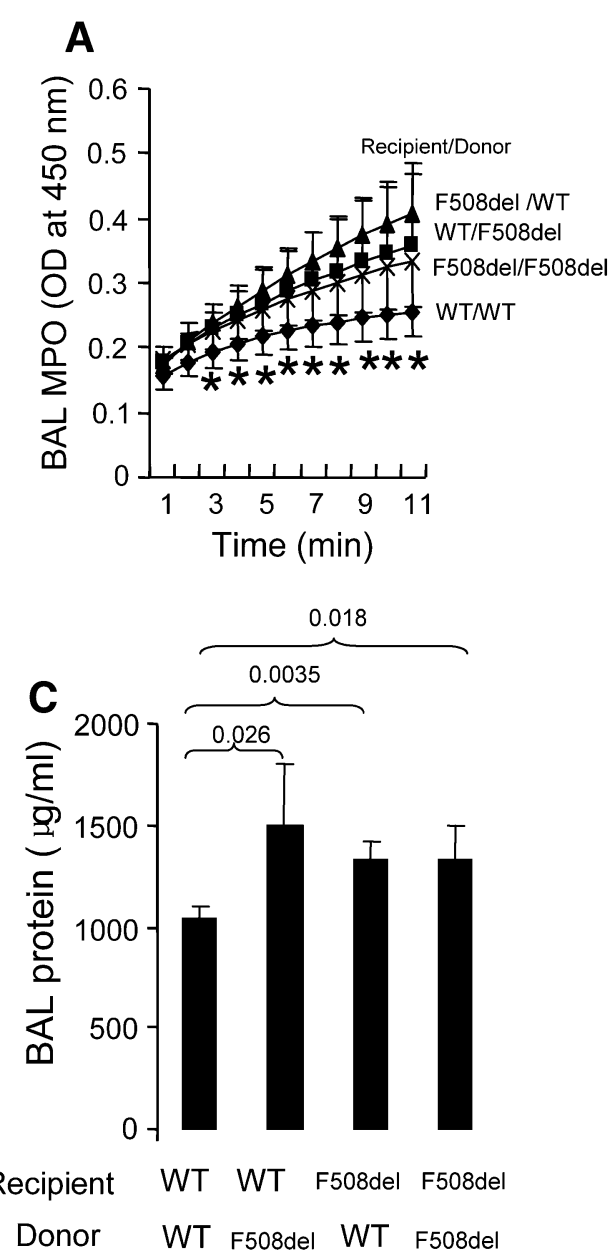

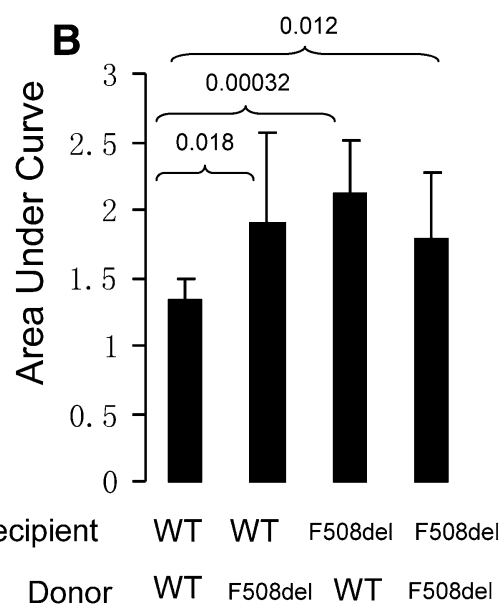

D

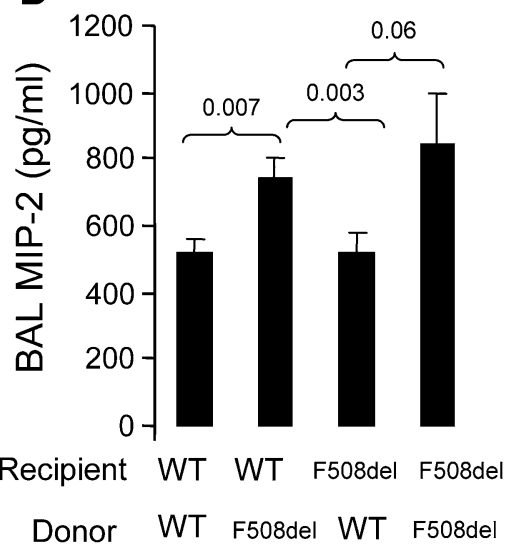

neutrophils displayed higher BAL neutrophil counts, MIP2 and $\mathrm{TNF}-\alpha$, and severe pulmonary edema comparing neutrophil-depleted wild-type mice reconstituted with wildtype neutrophils. Wild-type mice reconstituted with F508del bone marrow also demonstrated an elevated alveolar neutrophil transmigration, vascular permeability, and proinflammatory cytokine production (MIP-2) in response to intratracheal endotoxin exposure. Taken together, these findings also indicate that CFTR expressed by neutrophils modulates proinflammatory responses during LPS-induced acute lung inflammation and injury.

There is evidence that CF lung epithelia demonstrate a constitutive upregulation of the pro-inflammatory chemokine IL-8 and can increase IL-8 mRNA expression [35, 36] with LPS stimulation in a NF- $\kappa$ B dependent mechanism $[5,6,10,11]$. We found that F508del mice reconstituted with wild-type bone marrow exhibited higher BAL MPO and protein levels but without an increase in BAL MIP-2 compared to wild-type recipients reconstituted with wildtype bone marrow. The possible explanations include (1) F508del lung epithelial cells are more permeable to wild- type neutrophils; (2) F508del neutrophils are more potent than the wild-type neutrophils to illicit MIP-2 production by interacting with F508del macrophages or lung epithelial cells; and (3) there may be inflammation-limiting factors [37] in wild-type bone marrow to counteract the proinflammatory responses in F508del mice after LPS challenge.

There has been a long standing debate as to whether CFTR knockout or deltaF508 cells are more prone to inflammatory injury in the presence or absence of infection $[38,39]$; however, in the present experiments, inhibition or mutation of CFTR alone in neutrophils did not induce proinflammatory responses, and this occurred only after challenge with LPS, which also supports the hypothesis that CFTR is a modulator for sepsis-induced acute lung inflammation and injury.

Lung disease is the major cause of death in cystic fibrosis (CF). In a CFTR deficient ( $\mathrm{cftrm}^{1 \mathrm{HGU}}$ ) mouse model, capacity to clear Staphylococcus aureus and Burkholderia (Pseudomonas) cepacia-two opportunistic lung pathogens closely associated with lung disease in CF subjects-was impaired. In response to repeated microbial 


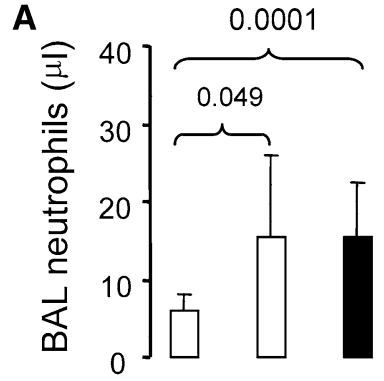

Recipient WT WT F508del Donor neutrophils WT F508del F508del

$$
\text { C }
$$

C 30000

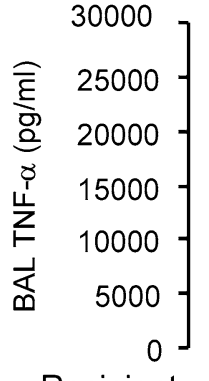

Recipient
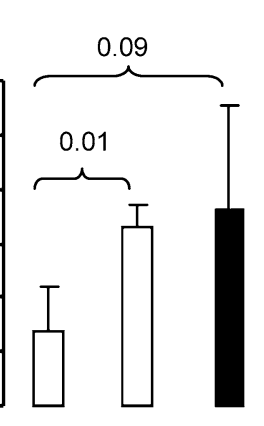

WT

Donor neutrophils WT F508del F508del

Fig. 9 Neutrophil reconstitution experiments demonstrate that F508del neutrophils are more proinflammatory in LPS-induced lung injury model. a Reconstitution of wild-type mice with F508del neutrophils promoted neutrophil recruitment into the airspaces of the lung compared to wild-type mice that received wild-type neutrophils. b, c Reconstitution of wild-type mice with F508del neutrophils increased BAL MIP-2 and TNF- $\alpha$ levels compared to wild-type mice

exposure, the $\mathrm{cftrm}^{1 \mathrm{HGU}}$ mice developed severe pulmonary edema, suggesting that lack of CFTR leads CF subjects to be susceptible to lung diseases and hyper-inflammatory responses [40].

Recently, Mckeon et al. [41] found that low levels of CFTR mRNA could be identified in normal human neutrophils, but CFTR protein was not found in human neutrophil lysates or immunoprecipitates. However, Painter et al. [10] fond that CFTR was present exclusively in the secretory vesicles of neutrophils. The CFTR chloride channel was also detected in phagolysosomes-a special organelle formed after phagocytosis. CFTR-mediated halide transport in the phagosomes of human neutrophils could be inhibited by thiazolidinone and glycine hydrazide [42]. In our study, we found that mouse neutrophils express CFTR under normal and LPS-stimulated conditions.

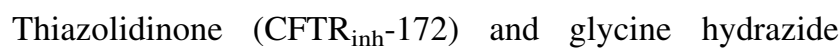
(MalH-2) CFTR inhibitors are able to inhibit CFTR expressed both on the cell membrane and in intracellular organelles because they are cell permeable [42, 43].
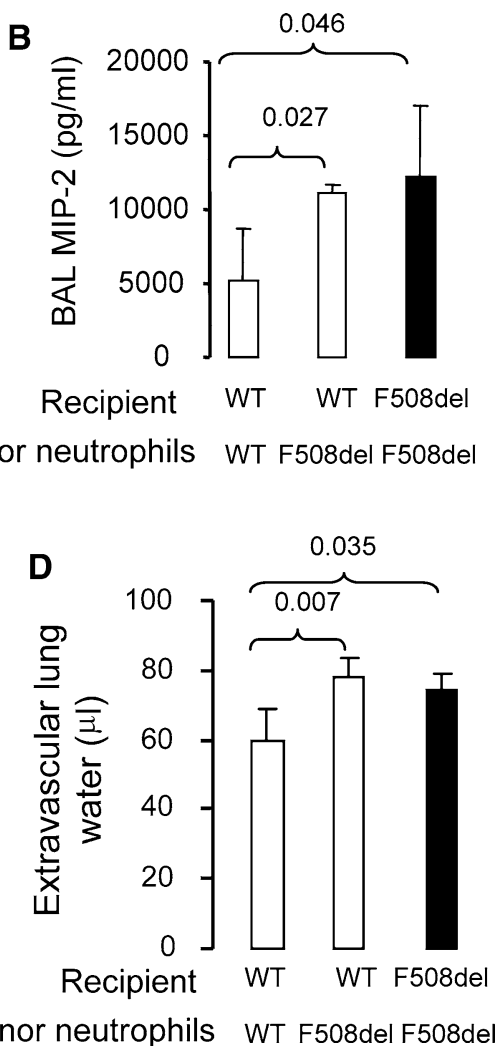

that received wild-type neutrophils. d Reconstitution of wild-type mice with F508del neutrophils worsened extravascular lung water compared to wild-type mice that received wild-type neutrophils at 24 h. $N=5-8$, in each group. $P<0.05$ or 0.01 for neutrophildepleted wild-type mice that received F508del neutrophils intravenously vs neutrophil-depleted wild-type mice that received wild-type neutrophils intravenously. Values are mean \pm SD

Although our findings may have relevance to $\mathrm{CF}$ patients who develop acute Gram negative sepsis from pneumonia or a non-pulmonary source, our findings do not explain the recurrent infection and excessive inflammation in CF airways [44, 45]. Further, another ion channel, such as NKCC1 [1], might play an important role in modulating inflammatory responses during sepsis-induced acute lung inflammation and injury.

In summary, we provide new evidence that lack of functional CFTR in neutrophils promotes production of proinflammatory cytokines by activation of NF- $\kappa \mathrm{B}$, and worsens LPS-induced acute lung inflammation and injury.

Acknowledgments This study was supported by NHLBI Grants HL-51854 and NIAID AI53194 (to M.A.M.), NHLBI HL082742 (to M.R.L.), HL093026 (to J.W.L.), and a Parker B. Francis Award (to X.S.). We appreciate G. M. Dolganov MD, PhD from Stanford University for performing quantitative PCR. We also want to thank N.D. Sonawane, Liman Qian, John Nguyen, and Yongmei Hu for their technical support and suggestions.

Conflict of interests The authors declare no financial interests. 
Open Access This article is distributed under the terms of the Creative Commons Attribution Noncommercial License which permits any noncommercial use, distribution, and reproduction in any medium, provided the original author(s) and source are credited.

\section{References}

1. Nguyen M, Pace AJ, Koller BH. Mice lacking NKCC1 are protected from development of bacteremia and hypothermic sepsis secondary to bacterial pneumonia. J Exp Med. 2007;204:1383-93.

2. Matthay MA, Su X. Pulmonary barriers to pneumonia and sepsis. Nat Med. 2007;13:780-1.

3. Courtney JM, Ennis M, Elborn JS. Cytokines and inflammatory mediators in cystic fibrosis. J Cyst Fibros. 2004;3:223-31.

4. Terheggen-Lagro SW, Rijkers GT, van der Ent CK. The role of airway epithelium and blood neutrophils in the inflammatory response in cystic fibrosis. J Cyst Fibros. 2005;4(Suppl 2):15-23.

5. Venkatakrishnan A, Stecenko AA, King G, Blackwell TR, Brigham KL, Christman JW, et al. Exaggerated activation of nuclear factor-kappaB and altered IkappaB-beta processing in cystic fibrosis bronchial epithelial cells. Am J Respir Cell Mol Biol. 2000;23:396-403.

6. Blackwell TS, Stecenko AA, Christman JW. Dysregulated NFkappaB activation in cystic fibrosis: evidence for a primary inflammatory disorder. Am J Physiol Lung Cell Mol Physiol. 2001;281:L69-70.

7. Perez A, Issler AC, Cotton CU, Kelley TJ, Verkman AS, Davis PB. CFTR inhibition mimics the cystic fibrosis inflammatory profile. Am J Physiol Lung Cell Mol Physiol. 2007;292:L383-95.

8. Vij N, Mazur S, Zeitlin PL. CFTR is a negative regulator of NFkappaB mediated innate immune response. PLoS One. 2009;4:e4664.

9. Di A, Brown ME, Deriy LV, Li C, Szeto FL, Chen Y, et al. CFTR regulates phagosome acidification in macrophages and alters bactericidal activity. Nat Cell Biol. 2006;8:933-44.

10. Painter RG, Valentine VG, Lanson NA Jr, Leidal K, Zhang Q, Lombard G, et al. CFTR expression in human neutrophils and the phagolysosomal chlorination defect in cystic fibrosis. Biochemistry. 2006;45:10260-9.

11. Thomas GR, Costelloe EA, Lunn DP, Stacey KJ, Delaney SJ, Passey R, et al. G551D cystic fibrosis mice exhibit abnormal regulation of inflammation in lungs and macrophages. J Immunol. 2000;164:3870-7.

12. Bruscia EM, Zhang PX, Ferreira E, Caputo C, Emerson JW, Tuck $\mathrm{D}$, et al. Macrophages directly contribute to the exaggerated inflammatory response in cystic fibrosis transmembrane conductance regulator-/- mice. Am J Respir Cell Mol Biol. 2009;40:295-304.

13. Corvol H, Fitting C, Chadelat K, Jacquot J, Tabary O, Boule M, et al. Distinct cytokine production by lung and blood neutrophils from children with cystic fibrosis. Am J Physiol Lung Cell Mol Physiol. 2003;284:L997-1003.

14. Wine JJ. The genesis of cystic fibrosis lung disease. J Clin Invest. 1999;103:309-12.

15. Engelhardt JF, Zepeda M, Cohn JA, Yankaskas JR, Wilson JM. Expression of the cystic fibrosis gene in adult human lung. J Clin Invest. 1994;93:737-49.

16. Tirouvanziam R, Khazaal I, Peault B. Primary inflammation in human cystic fibrosis small airways. Am J Physiol Lung Cell Mol Physiol. 2002;283:L445-51.

17. Ware LB, Matthay MA. The acute respiratory distress syndrome. N Engl J Med. 2000;342:1334-49.
18. Su X, Matthay MA, Malik AB.Requisite role of the cholinergic alpha7 nicotinic acetylcholine receptor pathway in suppressing Gram-negative sepsis-induced acute lung inflammatory injury. J Immunol. 2010;184:401-410

19. Ma T, Thiagarajah JR, Yang H, Sonawane ND, Folli C, Galietta LJ, et al. Thiazolidinone CFTR inhibitor identified by highthroughput screening blocks cholera toxin-induced intestinal fluid secretion. J Clin Invest. 2002;110:1651-8.

20. Sonawane ND, Hu J, Muanprasat C, Verkman AS. Luminally active, nonabsorbable CFTR inhibitors as potential therapy to reduce intestinal fluid loss in cholera. Faseb J. 2006;20: $130-2$.

21. Song Y, Sonawane ND, Salinas D, Qian L, Pedemonte N, Galietta LJ, et al. Evidence against the rescue of defective DeltaF508CFTR cellular processing by curcumin in cell culture and mouse models. J Biol Chem. 2004;279:40629-33.

22. Colledge WH, Abella BS, Southern KW, Ratcliff R, Jiang C, Cheng SH, et al. Generation and characterization of a delta F508 cystic fibrosis mouse model. Nat Genet. 1995;10:445-52.

23. Su X, Camerer E, Hamilton JR, Coughlin SR, Matthay MA. Protease-activated receptor- 2 activation induces acute lung inflammation by neuropeptide-dependent mechanisms. J Immunol. 2005;175:2598-605.

24. Su X, Johansen M, Looney MR, Brown EJ, Matthay MA. CD47 deficiency protects mice from lipopolysaccharide-induced acute lung injury and Escherichia coli pneumonia. J Immunol. 2008; 180:6947-53.

25. Lefort J, Singer M, Leduc D, Renesto P, Nahori MA, Huerre M, et al. Systemic administration of endotoxin induces bronchopulmonary hyperreactivity dissociated from TNF-alpha formation and neutrophil sequestration into the murine lungs. J Immunol. 1998;161:474-80.

26. Looney MR, Su X, Van Ziffle JA, Lowell CA, Matthay MA. Neutrophils and their $\mathrm{Fc}$ gamma receptors are essential in a mouse model of transfusion-related acute lung injury. J Clin Invest. 2006;116:1615-23.

27. Mocsai A, Abram CL, Jakus Z, Hu Y, Lanier LL, Lowell CA. Integrin signaling in neutrophils and macrophages uses adaptors containing immunoreceptor tyrosine-based activation motifs. Nat Immunol. 2006;7:1326-33.

28. Armstrong DA, Major JA, Chudyk A, Hamilton TA. Neutrophil chemoattractant genes KC and MIP-2 are expressed in different cell populations at sites of surgical injury. J Leukoc Biol. 2004;75:641-8.

29. Matzer SP, Baumann T, Lukacs NW, Rollinghoff M, Beuscher HU. Constitutive expression of macrophage-inflammatory protein 2 (MIP-2) mRNA in bone marrow gives rise to peripheral neutrophils with preformed MIP-2 protein. J Immunol. 2001;167: 4635-43.

30. Tsujimoto H, Ono S, Mochizuki H, Aosasa S, Majima T, Ueno C, et al. Role of macrophage inflammatory protein 2 in acute lung injury in murine peritonitis. J Surg Res. 2002;103:61-7.

31. Gupta S, Feng L, Yoshimura T, Redick J, Fu SM, Rose CE Jr. Intra-alveolar macrophage-inflammatory peptide 2 induces rapid neutrophil localization in the lung. Am J Respir Cell Mol Biol. 1996;15:656-63.

32. Goldblum SE, Hennig B, Jay M, Yoneda K, McClain CJ. Tumor necrosis factor alpha-induced pulmonary vascular endothelial injury. Infect Immun. 1989;57:1218-26.

33. Burdon PC, Martin C, Rankin SM. The CXC chemokine MIP-2 stimulates neutrophil mobilization from the rat bone marrow in a CD49d-dependent manner. Blood. 2005;105:2543-8.

34. Spight D, Zhao B, Haas M, Wert S, Denenberg A, Shanley TP. Immunoregulatory effects of regulated, lung-targeted expression of IL-10 in vivo. Am J Physiol Lung Cell Mol Physiol. 2005;288:L251-65. 
35. Tabary O, Zahm JM, Hinnrasky J, Couetil JP, Cornillet P, Guenounou $\mathrm{M}$, et al. Selective up-regulation of chemokine IL-8 expression in cystic fibrosis bronchial gland cells in vivo and in vitro. Am J Pathol. 1998;153:921-30.

36. Legssyer R, Huaux F, Lebacq J, Delos M, Marbaix E, Lebecque $\mathrm{P}$, et al. Azithromycin reduces spontaneous, induced inflammation in DeltaF508 cystic fibrosis mice. Respir Res. 2006;7:134.

37. Karp CL, Flick LM, Park KW, Softic S, Greer TM, Keledjian R, et al. Defective lipoxin-mediated anti-inflammatory activity in the cystic fibrosis airway. Nat Immunol. 2004;5:388-92.

38. Doring G, Conway SP, Heijerman HG, Hodson ME, Hoiby N, Smyth A, et al. Antibiotic therapy against Pseudomonas aeruginosa in cystic fibrosis: a European consensus. Eur Respir J. 2000;16:749-67.

39. Scheid P, Kempster L, Griesenbach U, Davies JC, Dewar A, Weber PP, et al. Inflammation in cystic fibrosis airways: relationship to increased bacterial adherence. Eur Respir J. 2001;17:27-35
40. Davidson DJ, Dorin JR, McLachlan G, Ranaldi V, Lamb D, Doherty $\mathrm{C}$, et al. Lung disease in the cystic fibrosis mouse exposed to bacterial pathogens. Nat Genet. 1995;9:351-7.

41. McKeon DJ, Cadwallader KA, Idris S, Cowburn AS, Pasteur MC, Barker H, et al. Cystic fibrosis neutrophils have normal intrinsic reactive oxygen species generation. Eur Respir J. 2010;35:1264-72.

42. Painter RG, Marrero L, Lombard GA, Valentine VG, Nauseef WM, Wang G. CFTR-mediated halide transport in phagosomes of human neutrophils. J Leukoc Biol. 2010;87:933-42.

43. Sonawane ND, Verkman AS. Thiazolidinone CFTR inhibitors with improved water solubility identified by structure-activity analysis. Bioorg Med Chem. 2008;16:8187-95.

44. Dechecchi MC, Nicolis E, Bezzerri V, Vella A, Colombatti M, Assael BM, et al. MPB-07 reduces the inflammatory response to Pseudomonas aeruginosa in cystic fibrosis bronchial cells. Am J Respir Cell Mol Biol. 2007;36:615-24.

45. Elizur A, Cannon CL, Ferkol TW. Airway inflammation in cystic fibrosis. Chest 2008;133:489-95. 